\title{
Pulmonary arterial hypertension associated with interferon therapy: a population-based study
}

\author{
Ravikanth Papani ${ }^{1 *} \mathbb{D}$, Alexander G. Duarte ${ }^{1}$, Yu-li Lin², Yong-Fang Kuo ${ }^{2}$ and Gulshan Sharma ${ }^{1}$
}

\begin{abstract}
Background: Isolated cases of pulmonary arterial hypertension (PAH) with interferon a or $\beta$ therapy have been reported, but no population-based estimates of the incidence of the disease after interferon exposure are available. The aim of this study was to determine the incidence of PAH after initiation of interferon therapy, using a large commercial insurance database.

Methods: Using National Drug Codes (NDCs) and Healthcare Common Procedure Coding System (HCPCS) codes, we utilized the Clinformatics ${ }^{\text {TM }}$ Data Mart (CDM) database to identify subjects between 20 and 65 years old who received a or $\beta$ interferon therapy between April 2001 and December 2012. Patients were followed from one year prior to the first medication claim for interferon to the first diagnosis of pulmonary hypertension using ICD-9-CM codes 416.0 and 416.8, or disenrollment. In those subjects diagnosed with pulmonary hypertension, a prescription for PAH-specific medications was used as a surrogate endpoint.

Results: We identified 20,113 subjects who received interferon therapy during the study period. The median follow-up was 20 months. Pulmonary hypertension occurred in 71 subjects, and PAH-specific medications were prescribed to 7 of these subjects.

Conclusion: Although our analysis showed that the development of PAH is a rare event with interferon therapy, the risk of developing the disease is several fold higher than that for the general population.
\end{abstract}

Keywords: Pulmonary arterial hypertension, Interferons, Drug toxicity

\section{Background}

In the last quarter of the $20^{\text {th }}$ century, type I interferons, including $\alpha$ and $\beta$, were introduced as treatment for malignancies, chronic viral infections, and chronic neurologic conditions $[1,2]$. Type I interferons are a family of glycoproteins with potent antiviral, immunomodulatory, and antitumor properties that are naturally generated in the human body, in response to pathogens and tumor cells. Consequently, interferon $\alpha$ was evaluated for the treatment of chronic hepatitis $C$ with reports of sustained virologic response with prevention of further hepatic fibrosis and progressive organ failure [3-5]. In the management of relapsing multiple sclerosis, interferon $\beta$ has been

\footnotetext{
* Correspondence: Ravikanth.papani@gmail.com

${ }^{1}$ Division of Pulmonary, Critical Care and Sleep Medicine, University of Texas Medical Branch, John Sealy Annex 5.140, 301 University Boulevard, Galveston, TX 77555, USA

Full list of author information is available at the end of the article
}

reported to decrease relapse rates and reduce disease burden when assessed by brain imaging $[6,7]$.

Although the benefits of interferon therapy are well documented, this medication has several side effects. It is commonly associated with flu-like illness and less often with neuropsychiatric effects (depression) and myelosuppression (pancytopenia). Occurrence of these side effects leads to dose reduction or delays in subsequent treatment and often resolve with drug discontinuation. Pulmonary arterial hypertension $(\mathrm{PAH})$, a rare but serious side effect of interferon therapy, was first reported in a patient with renal cancer [8]. As the indications for interferon expanded to include chronic hepatitis and multiple sclerosis, the frequency of reported cases of PAH increased [9-19]. Hence, a consensus group of experts categorized interferon $\alpha$ and $\beta$ as medications as possible risk factors for the development of PAH [20]. To 
investigate this association further, we developed a study with the aim of determining the incidence of $\mathrm{PAH}$ in a national population of patients living in the USA who were treated with $\alpha$ and $\beta$ interferon therapy.

\section{Methods}

\section{Study design and data source}

This retrospective cohort study was conducted using the Clinformatics $^{\text {Th }}$ Data Mart (CDM) Database (OptumInsight, Eden Prairie, Minnesota, USA), which contains data on 53 million private insurance enrollees in the USA. The database contains medical claims, pharmacy claims, and administrative data (member file) for the enrollees. Because our study was a secondary data analysis, it was classified as exempt research by the University of Texas Medical Branch Institutional Review Board (IRB).

\section{Study cohort}

We initially identified subjects who were started on interferon $\alpha$ or $\beta$ treatment between April 2001 and December 2012 (Fig. 1). From this cohort, we selected subjects with continuous enrollment in the prior year. We then selected those between 20 and 65 years old at treatment initiation. Finally, we identified subjects diagnosed with multiple sclerosis or hepatitis $C$ in the 3 months before the start of interferon treatment. We excluded subjects with a prior diagnosis of pulmonary hypertension. We used International Classification of Diseases, Ninth Revision, Clinical Modification (ICD-9-CM) codes to identify patients with multiple sclerosis (340), hepatitis C (070.41, 070.44, 070.51, 070.54, 070.70, and 070.71), and pulmonary hypertension (416.0 and 416.8), respectively. Interferon treatment was identified using National Drug Codes (NDCs) and Healthcare Common Procedure Coding System (HCPCS) codes J1825, J1826, J1830, J9212, J9213, J9214, J9215, J9216, Q3025, Q3026, S0145, S0146, and S0148. NDCs for interferons were identified with use of the RED BOOK ${ }^{\mathrm{Tm}}$ drug database (Truven Health Analytics Inc., Ann Arbor, Michigan, USA).

\section{Measures}

Age, gender, region, and follow-up time were obtained from the member file. We used claims for medical services in the year prior to interferon initiation to determine comorbidities, including connective tissue disorders, liver disease other than hepatitis C, HIV/AIDS, obesity, hypertension, congestive heart failure, valvular heart disease, chronic pulmonary disease, diabetes, and sleep apnea (Appendix).

\section{Outcomes}

The primary outcome of interest was $\mathrm{PAH}$, defined as new initiation of PAH-specific therapies following interferon therapy. The occurrence of pulmonary

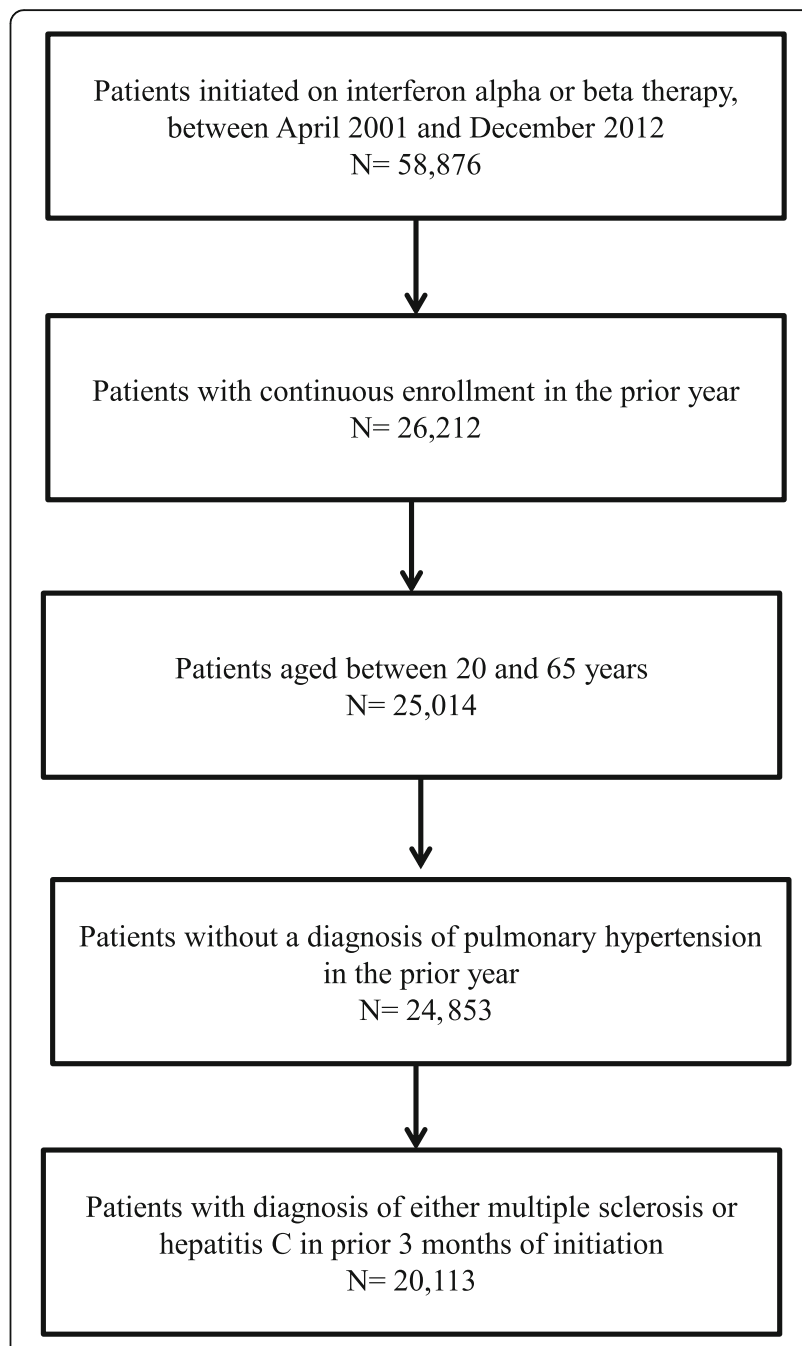

Fig. 1 Cohort selection in patients treated with alpha or beta interferons

hypertension was identified as the first ICD-9-CM code (416.0 or 416.8) registered following interferon therapy. Among those who developed the condition, we determined whether or not they received PAHspecific therapy, including ambrisentan, bosentan, epoprostenol, iloprost, macitentan, riociguat, sildenafil, tadalafil, and treprostinil. These medications were identified using NDCs and HCPCS codes J1325, Q4080, Q4074, J3285, Q4077, J7686, S0114, and S0090.

\section{Statistical analysis}

We determined the number and proportion of study subjects with each of the aforementioned measures. We then estimated the percent of subjects developing pulmonary hypertension by the Kaplan-Meier method and presented the result in graphics. Among those 
with a diagnosis of pulmonary hypertension, we estimated the proportion of subjects receiving PAHspecific medications by the Kaplan-Meier method. Cox proportional hazards regression was used to examine the factors associated with pulmonary hypertension. All statistical analyses were performed using SAS version 9.3 (SAS Inc., Cary, North Carolina, USA). The significance level was set at 0.05 .

\section{Results}

We identified 20,113 subjects treated with interferon therapy for either hepatitis $\mathrm{C}$ or multiple sclerosis between April 2001 and December 2012 (Fig. 1). Approximately two-thirds of the patients treated with interferon $\alpha$ or $\beta$ had hepatitis $C$ (Table 1). Mean age was $46.4 \pm 9.2$ years, and the majority of the patients were between 40 and 59 years old. Gender distribution was similar. Common comorbid conditions included hypertension and diabetes observed in 18 and 8\%, respectively. Other chronic liver conditions were recorded in 13\% of the group and included concomitant hepatitis B and alcohol-related liver disease. One in five patients on interferon therapy had at least one of the following cardiovascular conditions: hypertension, congestive heart failure, valvular heart disease, and atrial fibrillation. Other conditions associated with pulmonary hypertension-such as chronic lung disease, obstructive sleep apnea, connective tissue disorders, and HIV/AIDS-were less common. The median follow-up time was 20 months (mean $29.49 \pm 27.41$ ).

A total of 71 patients developed pulmonary hypertension during the study period, including 60 with hepatitis $C$ and 11 with multiple sclerosis. The mean age for this group was $52.4 \pm 33.5$ years, with males comprising $57.7 \%$ of the cohort. Common comorbidities included chronic liver disease other than hepatitis C (42.3\%), hypertension (33.8\%), and diabetes mellitus (22.5\%). The mean follow-up time for this group was $52.2 \pm$ 33.5 months.

Figure 2 presents the time to first diagnosis of pulmonary hypertension in this cohort, estimated by the Kaplan-Meier method, after initiation of interferon therapy. At 3, 6, and 9 years of follow-up time, $0.36,0.86$, and $1.77 \%$ of patients developed pulmonary hypertension, respectively. Table 2 shows the factors associated with the development of pulmonary hypertension based on Cox proportional hazards regression. The odds ratio (OR) of developing pulmonary hypertension was 4.32 (95\% CI 1.71-10.96) in patients with connective tissue disorders. Additional conditions associated with development of pulmonary hypertension included other liver disease excluding hepatitis C (OR 3.21; 95\% CI 1.93-5.34), valvular heart disease (OR 3.76; 95\% CI 1.16-12.21), and diabetes (OR 2.27; 95\% CI 1.25-4.11).
Table 1 Baseline characteristics of patients newly initiated on interferon therapy between 2001 and 2012

\begin{tabular}{|c|c|c|}
\hline Patient characteristics & Number & Percent \\
\hline \multicolumn{3}{|l|}{ Indication for interferon } \\
\hline Multiple sclerosis & 7190 & 35.75 \\
\hline Hepatitis C & 12,923 & 64.25 \\
\hline \multicolumn{3}{|l|}{ Age } \\
\hline $20-29$ & 1205 & 5.99 \\
\hline $30-39$ & 3154 & 15.68 \\
\hline $40-49$ & 7526 & 37.42 \\
\hline $50-59$ & 7084 & 35.22 \\
\hline $60-65$ & 1144 & 5.69 \\
\hline \multicolumn{3}{|l|}{ Gender } \\
\hline Male & 9906 & 49.25 \\
\hline Female & 10,207 & 50.75 \\
\hline \multicolumn{3}{|l|}{ Comorbidity $^{a}$} \\
\hline Hypertension & 3612 & 17.96 \\
\hline Other liver disease $\mathrm{e}^{\mathrm{b}}$ & 2647 & 13.16 \\
\hline Diabetes & 1589 & 7.90 \\
\hline Chronic pulmonary disease & 750 & 3.73 \\
\hline Sleep apnea & 338 & 1.68 \\
\hline Connective tissue disorder & 331 & 1.65 \\
\hline Obesity & 294 & 1.46 \\
\hline HIV/AIDS & 268 & 1.33 \\
\hline Valvular heart disease & 156 & 0.78 \\
\hline Congestive heart failure & 86 & 0.43 \\
\hline Atrial fibrillation and flutter & 74 & 0.37 \\
\hline \multirow[t]{2}{*}{ Congenital heart disease } & 8 & 0.04 \\
\hline & \multicolumn{2}{|c|}{ Mean \pm STD (Median) } \\
\hline Age & \multicolumn{2}{|c|}{$46.36 \pm 9.24(48.00)$} \\
\hline Follow-up time, months & \multicolumn{2}{|c|}{$29.49 \pm 27.41(20.00)$} \\
\hline
\end{tabular}

${ }^{\mathrm{a} A}$ patient could have more than one comorbidity. ${ }^{\mathrm{b}}$ Excluding hepatitis $C$

Among the 71 patients who developed pulmonary hypertension, 7 were treated with PAH-specific therapies, and 6 out of them were treated within five months from their diagnosis (Fig. 3). Treatment medications included sildenafil $(n=4)$, tadalafil $(n=1)$, epoprostenol $(n=1)$, and inhaled iloprost $(n=1)$.

\section{Discussion}

In this retrospective, administrative claims study of US patients with hepatitis $C$ and multiple sclerosis treated with interferon, a new diagnosis of pulmonary hypertension was recognized in 71 individuals, and 7 patients were prescribed PAH-specific therapies. At first glance, the incidence appears low. However, when compared to 


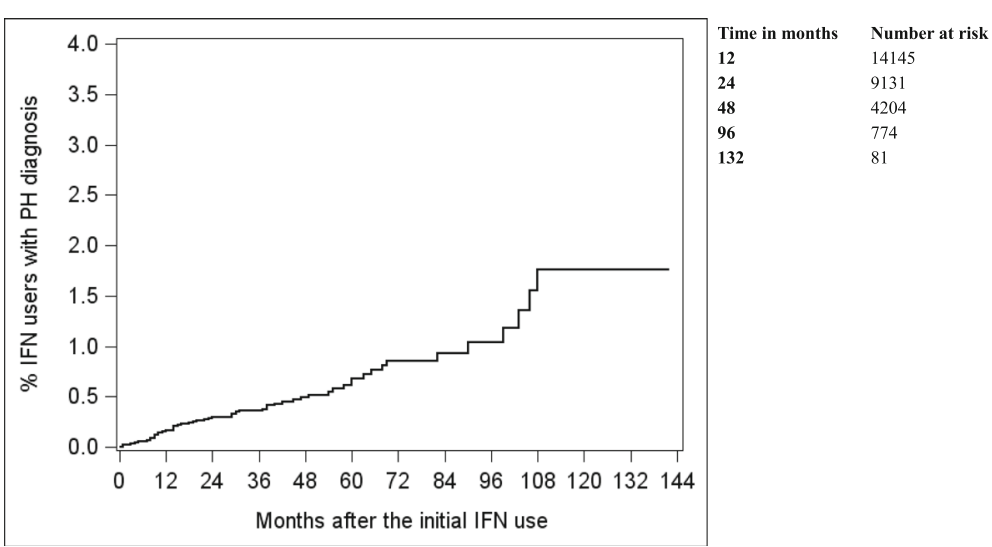

Fig. 2 Time to the first diagnosis of pulmonary hypertension diagnosis after interferon treatment. The percentages of patients diagnosed with pulmonary hypertension by year 3, 6, and 9 were $0.36,0.86$ and $1.77 \%$, respectively. IFN- interferons; $\mathrm{PH}$ - pulmonary hypertension

Table 2 Factors associated with the likelihood of developing pulmonary hypertension

\begin{tabular}{|c|c|}
\hline Patient characteristics & Hazard ratio $(95 \% \mathrm{Cl})$ \\
\hline \multicolumn{2}{|l|}{ Indication for interferon } \\
\hline Multiple sclerosis & Reference \\
\hline Hepatitis C & $1.43(0.69,2.96)$ \\
\hline \multicolumn{2}{|l|}{ Age } \\
\hline $20-29$ & Reference \\
\hline $30-39$ & $0.26(0.02,4.23)$ \\
\hline $40-49$ & $1.46(0.19,11.19)$ \\
\hline $50-59$ & $2.41(0.32,18.29)$ \\
\hline $60-65$ & $4.05(0.49,33.36)$ \\
\hline \multicolumn{2}{|l|}{ Gender } \\
\hline Male & Reference \\
\hline Female & $1.02(0.62,1.68)$ \\
\hline \multicolumn{2}{|l|}{ Comorbidity, Yes vs No } \\
\hline Hypertension & $1.43(0.84,2.43)$ \\
\hline Other liver disease ${ }^{a}$ & $3.21(1.93,5.34)$ \\
\hline Diabetes & $2.27(1.25,4.11)$ \\
\hline Chronic pulmonary disease & $1.92(0.82,4.50)$ \\
\hline Sleep apnea & $1.31(0.31,5.56)$ \\
\hline Connective tissue disorder & $4.32(1.71,10.96)$ \\
\hline Obesity & $0.73(0.10,5.51)$ \\
\hline HIV/AIDS & $2.63(0.63,10.89)$ \\
\hline Valvular disease & $3.76(1.16,12.21)$ \\
\hline Congestive heart failure & $1.10(0.15,8.17)$ \\
\hline
\end{tabular}

Note: Congenital heart disease and atrial fibrillation and flutter were not included in the model because there were no events among patients with such comorbidities. This model was adjusted for the year of the initial interferon treatment. ${ }^{\mathrm{a}}$ Does not include hepatitis $C$ the baseline risk in a general population, the incidence is quite substantial. To elaborate, the total person-years in our study cohort of 20,113 subjects was 49,360.5 personyears based on the follow-up time. Considering that the estimated incidence of $\mathrm{PAH}$ is 1.1 to 7.6 per million adults per year [21], we should have observed less than one PAH case in our study cohort. However, we identified 7 cases. This suggests that the risk of developing $\mathrm{PAH}$ in patients receiving interferon $\alpha$ or $\beta$ therapy is several fold higher than in general population.

Several drugs and toxins have been recognized as risk factors in the development of PAH and have been categorized based on the strength of evidence as definite, likely, possible, and unlikely [20]. Epidemiologic studies have determined a definite association between appetite suppressants as well as contaminated rapeseed oil with the development of PAH [22-24]. A consensus group of experts reviewed the evidence regarding the risk associated with development of PAH and designated $\alpha$ and $\beta$ interferons as possible risk factors [20]. In support of this, case reports have described new-onset PAH with interferon administration for treatment of chronic myelogenous leukemia, renal cell cancer, melanoma, chronic hepatitis, and multiple sclerosis [8-19]. Savale and colleagues described patients with newly diagnosed or worsening $\mathrm{PAH}$ associated with interferon therapy, from the French PAH registry [25]. In their case series, the majority of patients received interferon for treatment of chronic hepatitis $\mathrm{C}$ and hemodynamic measurements were performed to confirm the diagnosis. In addition, the majority of patients carried other risk factors for PAH, namely portal hypertension and/or HIV infection. Similarly, our study represents patients with hepatitis C and multiple sclerosis treated with interferon that developed pulmonary hypertension and subsequently received 


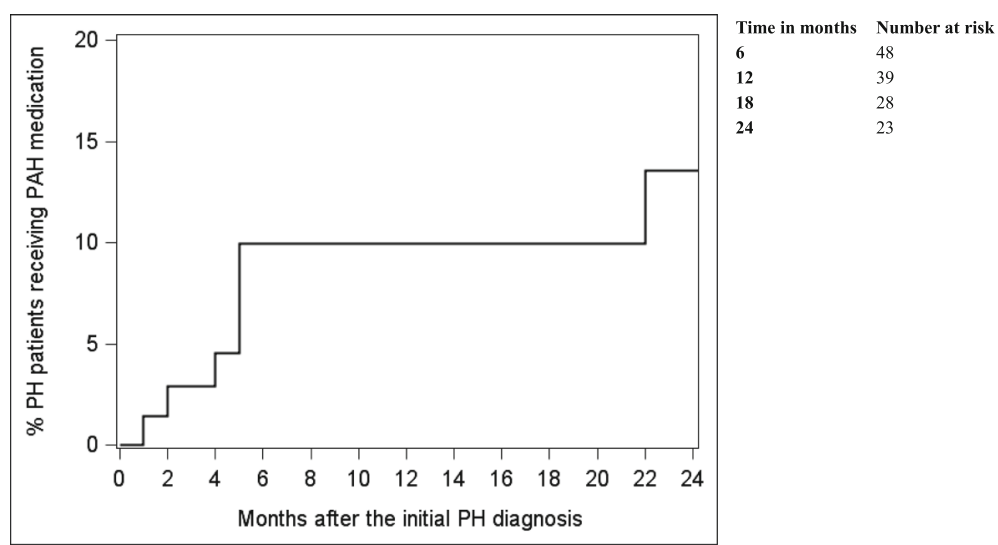

Fig. 3 Time to the first PAH medication after the first diagnosis of pulmonary hypertension. By the end of follow-up, 7 patients received medication, 6 out of them did so within the fifth month. IFN-interferons; PH-pulmonary hypertension

PAH-specific therapies. These reports support the association of $\alpha$ and $\beta$ interferons in the development of PAH.

There is a growing body of evidence implicating the role of inflammation and autoimmunity in the development of PAH, and this has produced work examining the role of interferons in pulmonary vascular pathology [26, 27]. Endothelin-1 is a well-established mediator in the pathogenesis of PAH and is overexpressed in patients with PAH [28]. Elevated endothelin was found in patients receiving interferon $\alpha$ therapy for chronic hepatitis $C$, and the dependent increase in serum endothelin levels seen in these patients was related to interferon and not to the virus [29]. A group of investigators systematically addressed the role of interferon in $\mathrm{PAH}$, using in vitro and in vivo experimental models as well as clinical samples from patients with scleroderma with and without PAH [30]. They noted that type I interferons induced endothelin-1 release from human pulmonary artery smooth muscle cells. Mice lacking functional type I interferon receptor (IFNAR $1^{-/-}$) were protected from the effects of hypoxia and development of PAH. When clinical samples were analyzed, a greater number of scleroderma patients with $\mathrm{PAH}$ had detectable levels of interferons, along with significantly higher levels of endothelin-1, when compared to patients without PAH. Apart from elevated serum levels of interferons and endothelins, interferon receptor expression was also increased in lung sections of scleroderma patients with PAH. Thus, investigators concluded that type I interferons, their receptors, and downstream mediators are associated with PAH. Collectively, these reports provide an underlying mechanism by which type I interferon results in the development of PAH.
Our study has several limitations. An important limitation concerns the use of ICD-9 codes for the diagnosis of PAH. Prior investigations have indicated that these codes do not adequately distinguish PAH from non-PAH patients [31-33]. To address this issue, we only examined patients who were treated with $\mathrm{PAH}$-specific therapies, thereby focusing on patients for whom the treating physician had sufficient evidence to prescribe PAH-specific therapies. In addition, we identified patients with continuous enrollment lacking an ICD-9 code diagnosis for pulmonary hypertension in the preceding one year. While, hemodynamic data were not available in this database, we believe that a prescription for $\mathrm{PAH}$-specific therapy indicates a provider's clinical diagnosis of PAH. We assume that an ICD code and subsequent prescription for PAH-specific therapy represents a "real world" diagnosis of PAH. Another limitation concerns the duration of follow-up. Our data was extracted from a large insurance claims database, and enrollees often discontinued their insurance policies when they switched to different employers who purchase insurance plans from other insurance carriers. Therefore, the dropout rate was high. Reports regarding interferon-induced PAH indicate that onset of the pulmonary vascular disease process may take up to 5 years, and our study may underestimate the incidence. Lastly, although our study cohort had several comorbidities that are independent risk factors for $\mathrm{PAH}$, their prevalence in the cohort was much less than in general population.

\section{Conclusion}

Using an administrative claims database, we found that the frequency of PAH in interferon-treated hepatitis $\mathrm{C}$ or multiple sclerosis patients was several fold higher than that for the general US population. 


\section{Appendix}

Table 3 ICD-9-CM codes used for identifying comorbidities

\begin{tabular}{ll}
\hline Comorbidity & ICD-9-CM \\
\hline Connective tissue disorder & $446,701.0,710.0,710.1,710.2,710.3,710.4,710.8,710.9,711.2,714,719.3,720,725,728.5,728.89,729.30$ \\
Other liver disease & $070.22,070.23,070.32,070.33,070.6,070.9,456.0,456.1,456.2,570,571,572.2,572.3,572.4,572.8,573.3$, \\
& $573.4,573.8,573.9$, V42.7 \\
HIV/AIDS & $042,043,044$ \\
Obesity & 278.0 \\
Hypertension & $401,402,403,404,405$ \\
Congestive heart failure & $398.91,402.01,402.11,402.91,404.01,404.03,404.11,404.13,404.91,404.93,425.4,425.5,425.7,425.8,425.9,428$ \\
Valvular disease & $093.2,394,395,396,397,424,746.3,746.4,746.5,746.6$, V42.2, V43.3 \\
Chronic pulmonary disease & $416.9,490,491,492,493,494,495,496,500,501,502,503,504,505,506.4,508.1,508.8$ \\
Diabetes & $250.0,250.1,250.2,250.3,250.4,250.5,250.6,250.7,250.8,250.9$ \\
Congenital heart disease & $746.9,745.4$ \\
Atrial fibrillation and flutter & 427.3 \\
Sleep apnea & $327.21,327.23,327.27,780.51,780.53,780.57,786.03,786.04$ \\
\hline
\end{tabular}

For each of the comorbidities, the study subjects needed to have 2 claims separated by at least 30 days in the year before the interferon initiation to be considered to have that comorbidity

\section{Acknowledgements}

The authors thank Leonard W. Pechacek for his assistance with manuscript preparations, and all the faculty and fellows from pulmonary division, University of Texas Medical Branch at Galveston, for their support.

\section{Funding}

None.

\section{Availability of data and materials}

Data cannot be made publicly available by the authors, as they were obtained by a third party, Optumlnsight. Authors may request the data from Optumlnsight (link: https://www.optum.com/contact/sales-inquiry.html; phone number: 1-866-386-3404)

\section{Authors' contributions}

$\mathrm{RP}$ contributed to conception and design, data analysis, manuscript writing and editing; $A D$ contributed to data analysis, manuscript drafting and editing; YLL contributed to data acquisition, data management, data analysis, manuscript editing; YFK contributed to data analysis and manuscript editing; GS contributed to the design, data analysis, manuscript drafting and editing. All authors read and approved the final manuscript.

\section{Competing interests}

GS reports personal fees from Sunovion Pharmaceuticals and Mylan Pharmaceuticals, outside the submitted work. Rest of the authors has nothing to disclose.

\section{Consent for publication}

Not applicable.

\section{Ethics approval and consent to participate}

The study was classified as exempt research by the University of Texas Medical Branch Institutional Review Board (IRB).

\section{Author details}

'Division of Pulmonary, Critical Care and Sleep Medicine, University of Texas Medical Branch, John Sealy Annex 5.140, 301 University Boulevard, Galveston, TX 77555, USA. ${ }^{2}$ Office of Biostatistics, Department of Preventive Medicine and Community Health, University of Texas Medical Branch, 301 University Boulevard, Galveston, TX, USA.
Received: 11 November 2016 Accepted: 14 December 2016

Published online: 17 January 2017

References

1. Borden EC. Interferons: rationale for clinical trials in neoplastic disease. Ann Intern Med. 1979;91:472-9.

2. George PM, Badiger R, Alazawi W, et al. Pharmacology and therapeutic potential of interferons. Pharmacol Ther. 2012;135:44-53.

3. Hoofnagle JH, Mullen KD, Jones DB, et al. Treatment of chronic non-A, non-B hepatitis with recombinant human alpha interferon. a preliminary report. N Engl J Med. 1986;315:1575-8.

4. Davis GL, Balart LA, Schiff ER, et al. Treatment of chronic hepatitis C with recombinant interferon alpha. A multicenter randomized, controlled trial. Hepatitis Interventional Therapy Group. N Engl J Med. 1989;321:1501-6.

5. McHutchison JG, Gordon SC, Schiff ER, et al. Interferon alfa-2b alone or in combination with ribavirin as initial treatment for chronic hepatitis C. Hepatitis Interventional Therapy Group. N Engl J Med. 1998;339:1485-92.

6. Paty D W, Li D K. Interferon beta-1b is effective in relapsing-remitting multiple sclerosis. II. MRI analysis results of a multicenter, randomized, double blind, placebo-controlled trial. UBC MS/MRI Study Group and the IFNB Multiple Sclerosis Study Group. Neurology. 1993;43:662-7.

7. IFNB Multiple Sclerosis Study Group. Interferon beta-1b in the treatment of multiple sclerosis: final outcome of the randomized controlled trial. The IFNB Multiple Sclerosis Study Group and The University of British Columbia MS/MRI Analysis Group. Neurology. 1995;45:1277-85.

8. Kramers $\mathrm{C}$ de Mulder $\mathrm{PH}$, Barth JD, et al. Acute right ventricular heart failure in a patient with renal cell carcinoma after interferon therapy. Neth J Med. 1993:42:65-8.

9. Fruehauf S, Steiger S, Topaly J, et al. Pulmonary artery hypertension during interferon-alpha therapy for chronic myelogenous leukemia. Ann Hematol. 2001;80:308-10.

10. Anderson $P$, Höglund M, Rödjer S. Pulmonary side effects of interferon alpha therapy in patients with hematological malignancies. Am J Hematol. 2003;73:54-8.

11. Jochmann $\mathrm{N}$, Kiecker F, Borges $A C$, et al. Long-term therapy of interferonalpha induced pulmonary arterial hypertension with different PDE-5 inhibitors: a case report. Cardiovasc Ultrasound. 2005:3:26.

12. Ledinek AH, Jazbec SS, Drinovec I, et al. Pulmonary arterial hypertension associated with interferon $\beta$ treatment for multiple sclerosis: a case report. Mult Scler. 2009;15:885-6. 
13. Dhillon S, Kaker A, Dosanjh A, et al. Irreversible pulmonary hypertension associated with the use of interferon alpha for chronic hepatitis C. Dig Dis Sci. 2010;55:1785-90.

14. Caravita S, Secchi MB, Wu SC, et al. Sildenafil therapy for interferon $\beta$-1a-induced pulmonary arterial hypertension: a case report. Cardiology. 2011;120:187-9.

15. Prella M, Yerly $P$, Nicod LP, et al. Pulmonary arterial hypertension in patients treated with interferon. Eur Respir J. 2015;46:1849-51.

16. Govern EM, Judge EP, Kavanagh E, Gaine $S$, Lynch T. Interferon $\beta$ related pulmonary arterial hypertension; an emerging worrying entity? Mult Scler Relat Disord. 2015;4:284-6.

17. Gibbons E, Promislow S, Davies RA, et al. Reversible pulmonary arterial hypertension associated with interferon- $\beta$ treatment for multiple sclerosis. Can Respir J. 2015;22:263-5.

18. Fok A, Williams T, McLean CA, et al. Interferon beta-1a long-term therapy related to pulmonary arterial hypertension in multiple sclerosis patients. Mult Scler Epub. 2016;22(11):1495-8.

19. Baghizadeh S, Sahraian MA, Ghahari M. Reversible pulmonary artery hypertension in association with interferon-beta therapy for multiple sclerosis. Iran J Neurol. 2016;15:54-6.

20. Simonneau G, Gatzoulis A, Adatia I, et al. Updated clinical classification of pulmonary hypertension. J Am Coll Cardiol. 2013;62(Suppl. 25):D34-41.

21. Hoeper MM, Humbert M, Souza R, et al. A global view of pulmonary hypertension. Lancet Respir Med. 2016;4:306-22.

22. Abenhaim L, Moride Y, Brenot F, et al. Appetite-suppressant drugs and the risk of primary pulmonary hypertension. International Primary Pulmonary Hypertension Study Group. N Engl J Med. 1996;335:609-16.

23. Gurtner HP. Aminorex and pulmonary hypertension. A review. Cor Vasa. 1985;27:160-71.

24. Posada de la Paz M, Philen RM, Borda Al. Toxic oil syndrome: the perspective after 20 years. Epidemiol Rev. 2001;23:231-47.

25. Savale L, Sattler C, Gunther S, Montani D, et al. Pulmonary arterial hypertension in patients treated with interferon. Eur Respir J. 2014;44:1627-34.

26. Eloranta ML, Franck-Larsson K, Lövgren T, et al. Type I interferon system activation and association with disease manifestations in systemic sclerosis. Ann Rheum Dis. 2010;69:1396-402.

27. Nicolls MR, Taraseviciene-Stewart L, Rai PR, et al. Autoimmunity and pulmonary hypertension: a perspective. Eur Respir J. 2005;26:1110-8

28. Giaid A, Yanagisawa M, Langleben D, et al. Expression of endothelin-1 in the lungs of patients with pulmonary hypertension. $\mathrm{N}$ Engl J Med. 1993;328:1732-9.

29. George PM, Cunningham ME, Galloway-Phillipps N, et al. Endothelin-1 as a mediator and potential biomarker for interferon induced pulmonary toxicity. Pulm Circ. 2012;2:501-4.

30. George PM, Oliver E, Dorfmuller P, et al. Evidence for the involvement of type interferon in pulmonary arterial hypertension. Circ Res. 2014;114:677-88.

31. Hyduk A, Croft JB, Ayala C, et al. Pulmonary hypertension surveillanceUnited States, 1980-2002. MMWR Surveill Summ. 2005;54:1-28.

32. Link J, Glazer C, Torres F, et al. International Classification of Diseases coding changes lead to profound declines in reported idiopathic pulmonary arterial hypertension mortality and hospitalizations: implications for database studies. Chest. 2011;139:497-504.

33. George MG, Schieb LJ, Ayala C, et al. Pulmonary hypertension surveillance: United States, 2001 to 2010. Chest. 2014;146:476-95.

\section{Submit your next manuscript to BioMed Central and we will help you at every step:}

- We accept pre-submission inquiries

- Our selector tool helps you to find the most relevant journal

- We provide round the clock customer support

- Convenient online submission

- Thorough peer review

- Inclusion in PubMed and all major indexing services

- Maximum visibility for your research

Submit your manuscript at www.biomedcentral.com/submit

C Biomed Central 